\title{
Interactions of biogeochemical cycles
}

\section{from Bert Bolin}

CARBON, nitrogen, phosphorus and sulphur and of course hydrogen and oxygen are needed in precise proportion for the formation of the fundamental molecules on which life depends. Their availability, interactions and circulation in nature have therefore been decisive to development of life on Earth and to maintenance of the present global ecosystem. The development of living organisms in turn substantially modified the primordial distributions and circulation of these basic elements. Since the mid 1970s, the Scientific Committee on Problems of the Environment (SCOPE) has been studying the global cycles of carbon, nitrogen, phosphorus and sulphur, and in particular, the overall balance of the material fluxes due to air and water motion. It is hoped that the long-term impact of man's wastes on the ecosystem can be effectively analysed and possible future changes foreseen. A SCOPE workshop* was held recently outside Stockholm to survey our present knowledge.

In the atmosphere the fundamental role of the hydroxyl radical $(\mathrm{OH})$ formed when oxygen is photodissociated and the exited oxygen atoms react with water, has been firmly established. It oxidizes $\mathrm{CH}_{4}$ and $\mathrm{CO}$ to $\mathrm{CO}_{2}, \mathrm{NO}$ and $\mathrm{NO}_{2}\left(\mathrm{NO}_{\mathrm{X}}\right)$ to nitrate and reduced sulphur compounds and $\mathrm{SO}_{2}$ to sulphate. The $\mathrm{C}, \mathrm{N}$ and $\mathrm{S}$ cycles are thus coupled and their interactions have changed during the evolution of the atmosphere.

Terrestrial ecosystems have been able to establish nearly closed circulation patterns to economize on nutrients, which are often in limited supply. To foresee possible future changes we need to understand how these systems have evolved. In the hydrosphere running water is an important agent for translocation of all the nutrients on land and for the slow transfer from land to sea. However, an approximate steady state of the $\mathrm{N}$ and $\mathrm{S}$ cycles has been maintained over the past few millenia by the return flow from the sea to land via air motions.

Human activity is now inducing fluxes of carbon, nitrogen, phosphorous and sulphur comparable in magnitude to natural fluxes. The annual release of $\mathrm{CO}_{2}$ fossil fuels is about 10 per cent of that used in natural primary production by terrestrial plants. It is not certain how photosynthesis and biomass accumulation on land may change due to this disturbance, and it became apparent at the workshop that the

* The international workshop on the Interaction of biogeochemical cycles took place at (irsundsbro outside Stockholm on 25-30. Nay 1981 with financial support from UNEP. The outcome of the meeting will appear as SC(UPE report (no.24). Reports nos 7, 13 and 16 summarize previou workshops and symposia, and no.17 will soon be published, on the SC (OPE General Assembly held in Stockholm in June 1979. pathways of the excess $\mathrm{CO}_{2}$ would be resolved only by examining the interplay of the $\mathrm{N}$ and $\mathrm{P}$ cycles with the carbon cycle.

The amount of $\mathrm{NO}_{\mathrm{X}}$ and $\mathrm{NO}_{3}$ formed in fossil fuel combustion and fertilizer manufacturing is about one-half of that produced naturally by the biosphere. Nitrogen oxides ( $\mathrm{NO}$ and $\mathrm{NO}_{2}$ ) are important in tropospheric ozone reactions: above a critical $\mathrm{NO}_{\mathrm{X}}$ concentration ozone is created as a by-product of the photochemical oxidation of hydrocarbons. Hence tropospheric ozone in the Northern Hemisphere may have increased signficantly due to the man's impact on the $\mathrm{N}$ cycle. In contrast, the photochemical influence of $\mathrm{NO}_{\mathrm{X}}$ on the stratospheric ozone distribution leads to ozone depletion. Enhanced nitrogen loading to terrestrial systems resulting from fossil fuel combustion may increase net primary production (including forest biomass) due to the fertilizing effect of $\mathrm{N}$, and enhanced $\mathrm{N}$ and $\mathrm{P}$ loading to rivers (see below) is likely to lead to the eutrophication of coastal waters and an increase in organic matter sedimentation.

$\mathrm{SO}_{2}$ emission to the atmosphere, primarily by fossil fuel combustion, probably exceeds the exchange of sulphur (excluding sulphur in sea spray) by air motions between land and sea. The oxidation of $\mathrm{SO}_{2}$ to $\mathrm{H}_{2} \mathrm{SO}_{4}$ and its deposition near main industrial areas is acidifying the lakes of Scandinavia, Canada and the northeastern US, with damaging effects on the biota. Most terrestrial ecosystems are relatively well buffered with respect to $p \mathrm{H}$ and direct toxic effects of incresed acidity have only been conclusively established in restricted areas. An indirect effect of acidification is the increasing levels of aluminium, which is toxic to roots, in the ground water. Nitric acid, produced from the oxidation of $\mathrm{NO}_{\mathrm{X}}$, has also contributed to the increased acidity of precipitation. The increased input of ammonia, which has taken place simultaneously as a result of growth in agriculture and increased use of nitrogen fertilizers, has only partially balanced the increased acidification due to sulphuric and nitric acids.

Industrial emissions, particularly of $\mathrm{SO}_{2}$, have led to a change in visibility of the atmosphere due to the formation of ammonium sulphate. Together with the urban photochemical smog produced from automobiles exhaust gases, in particular $\mathrm{NO}_{\mathrm{x}}$, a dramatic change in the environment is being produced. Chemical interaction of $\mathrm{N}$ and $\mathrm{S}$ in the atmosphere leads to changes in their atmospheric residence times and will bring about an increase in the size of the affected areas, particularly as fossil fuel burning increases in the future.

As a consequence of the widespread use of fertilizers, detergents and industrial chemicals containing $\mathrm{N}$ and $\mathrm{P}$, the riverine fluxes of these elements seems to have increased about twofold over the past $30 \mathrm{yr}$ resulting in increased biological activity in rivers and coastal zones. The increased supply of organic detritus from plant production in the photic zone will enhance the amount of carbon stored in the sediments. Algae at the base of the food chain are replaced by less desirable species and the areas of anoxia increase. Coastal waters are essential to man both because the human population is concentrated along the shores and because the sea is an important source of food. Our understanding of coastal ecosystems is by no means adequate to judge how man is modifying the waters and ocean floor along the shores.

Present methods of cultivation cause substantial losses of $\mathrm{C}, \mathrm{N}, \mathrm{P}$ and $\mathrm{S}$ from terrestrial ecosystems through accelerated decomposition, reduced additions of structural organic material to the soil, increased erosion and the removal of $\mathrm{N}, \mathrm{P}$ and $\mathrm{S}$ in harvested products. However, by using alternative strategies for land management, which balance the net input of organic $\mathrm{C}, \mathrm{N}, \mathrm{P}$ and $\mathrm{S}$, and thereby simulate the interacting nutrient cycles of natural terrestrial ecosystems, loss of soil fertility can be minimized and the organic matter, nutrient content and productivity of degraded sites even increased.

An additional problem is the aging of soils over millions of years associated with the transformation of phosphorus into biologically inaccessible compounds. In the light of marked changes in soils, particularly in the arid and semi-arid regions, long-term strategies for soil management are urgently needed.

Man's effect on the C, N, P and S cycles and their interactions in the global ecosystem are becoming clearer. We have learned that disturbances in one region of the world may affect the world as a whole, but quantitative models of the key biogeochemical cycles are still very crude. In the future, an approach similar to that used in climate modelling needs be adopted. It is now clear that an understanding of the main features of the general circulation of the atmosphere and the oceans are crucial for modelling the biogeochemical cycles and conversely, climate and climatic change cannot be understood without knowledge of the biogeochemical cycles.

Bert Bolin is Professor in the Department of Meteorology at the University of Stockholm. 